\title{
On Employment of FRP Elements in Constructions: The Case of an All GFRP Covering for Historic Structure Stroked by Earthquake
}

\author{
Salvatore Russo \\ University IUAV of Venice, Convento delle Terese 2206, Venice 30172, Italy
}

\begin{abstract}
The paper shows the approach toward the calculation of one of the bigger PFRP (Pultruded Fiber Reinforced Polymer) structure realized in high seismic zone, i.e., a covering structure of an historic church stroked and partially collapsed by earthquake in L'Aquila (Italy), the 4 April 2009. The goal regards the analysis and evaluation of seismic performance of that structure made by very light and elastic-brittle material, as FRP material, in a moment in which there is a loss of technical recommendation for specific calculation in seismic field, indeed actually some deepening already present in literature allows only static field. The covering structure is an all FRP spatial-reticular with elements made by pultrusion process, connection plates by bag molding process and steel bolts. The PFRP structure covers more than 1000 meters squares surface with 32 meters height and only $100 \mathrm{kN}$ weight. Detail performance of first part of PFRP structure through mode vibrations and involved percentage mass deduced by numerical approach with discussion of employment's perspectives of PFRP material in seismic zones than traditional material are showed.
\end{abstract}

Key words: Pultruded FRP profile, seismic performance, mode of vibration.

\section{Introduction}

The research put work on seismic criteria adopted to realize an all PFRP spatial structure - one of the bigger in the world - as a covering of very old church stroked by earthquake in L'Aquila (Italy) in 2009. The goal is very innovative [1] as for specific technical recommendation for analytical approach on PFRP structures in seismic zone are not yet available. First of all the complexity is due in fact to the elastic brittle constitutive low of FRP material, the anisotropic behavior and the very reduced weight, from 1600 to $1800 \mathrm{~kg} / \mathrm{m}^{3}$.

Many papers and technical recommendations regarding only static field, i.e., Refs. [2-7], are present, and also in Italy also there is a similar situation with strongly limitation in seismic zone due first to the absence of plasticity in FRP material $[8,9]$. Several

Corresponding author: Salvatore Russo, professor, research fields: structural health monitoring, FRP material, high performance concrete. E-mail: russo@iuav.it. researches show the potentility of this new technology $[10,11]$. Some picture of the PFRP structure put inside of historical church are presented in Figs. 1-2. Fig. 1a shows the global 3D view, while the Figs. 1b-1c depict the transversal and longitudinal section respectively. The FRP profiles, all-composite structures and others structural element are characterized by low frequency and high time of dissipation [12-17]; while stiffness remain constant till the collapse and very low mass and the high deformability reduce respectively the seismic action and the shear strength [8]. The structure is reticular and spatial on superficial reinforced concrete foundations, every element has been realized through a composite cross section made by four "C" shape bolted PFRP profiles. As showed by Fig. 2 the meaning of the PFRP structure is a temporary structure even if the high complexity of restoration and economic support needed do that PFRP structure will remain there as protection at least for the next five years. The seismic calculation has been carried out even if we have had a permanent structure. 


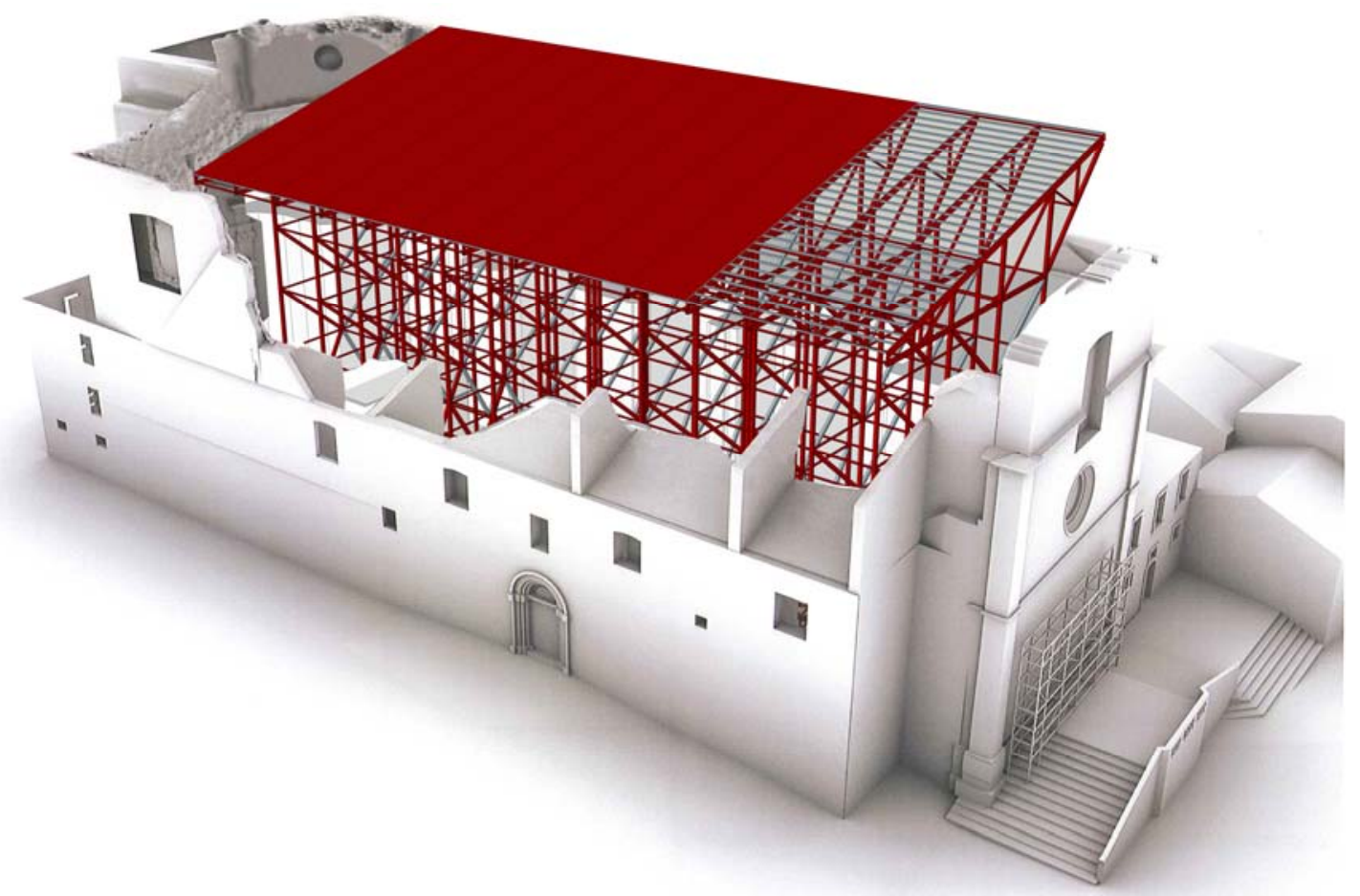

Fig. 1a 3D view of PFRP spatial structure in S. M. Paganica church.

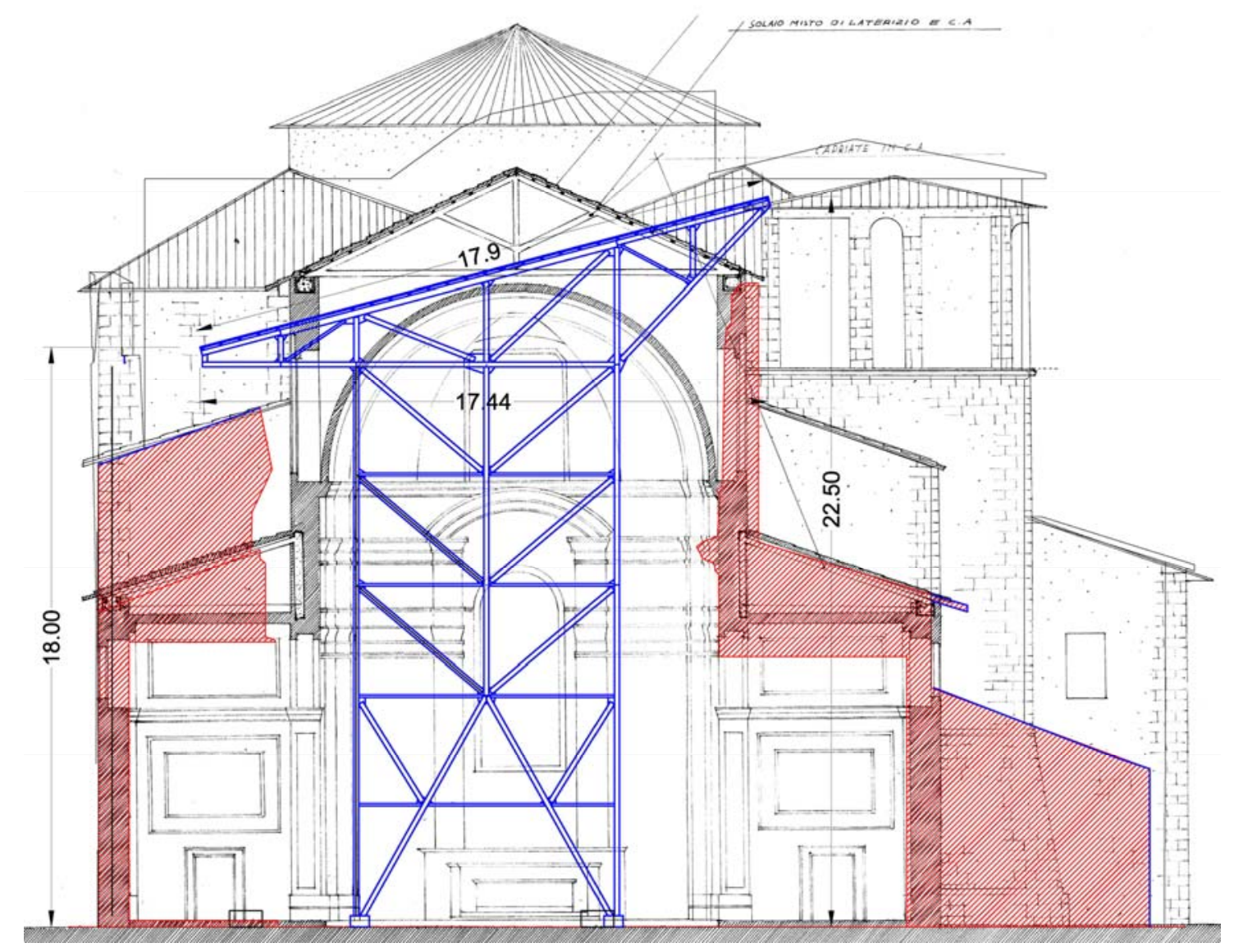

Fig. 1b Transversal section. 


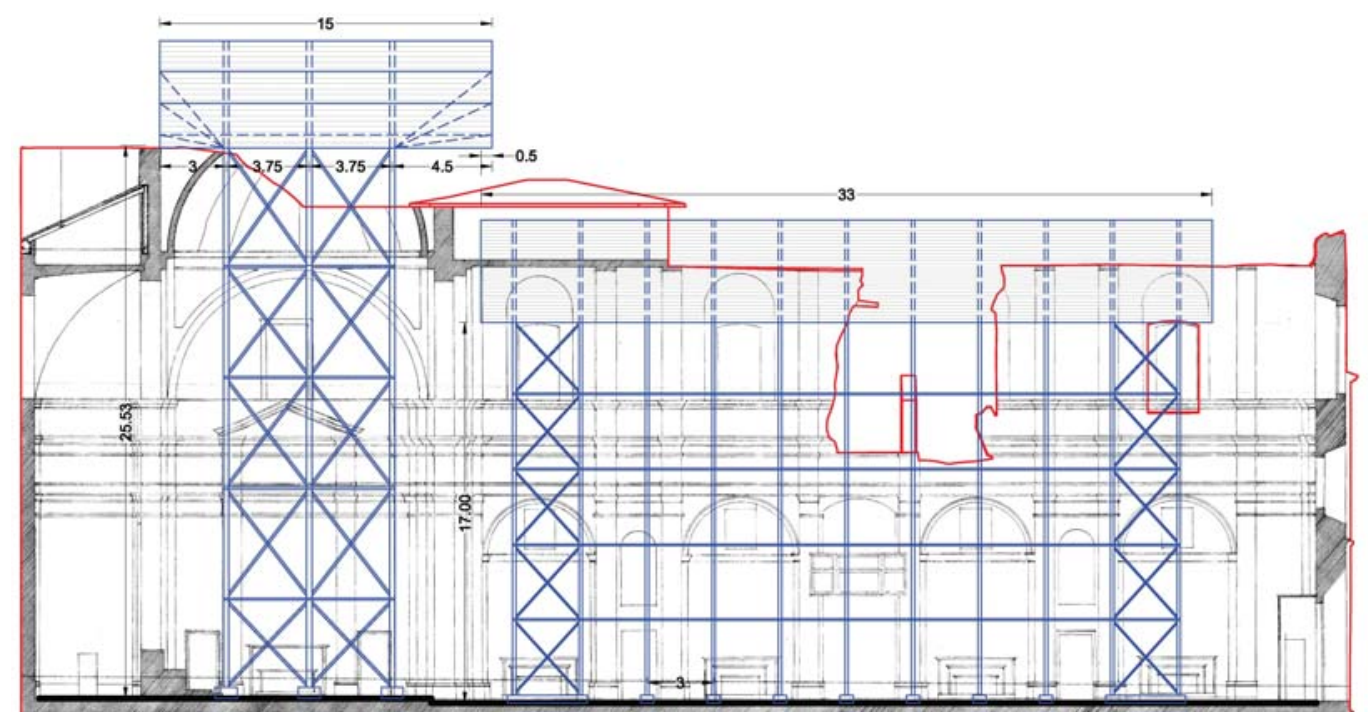

Fig. 1c Longitudinal section.

Fig. 2a S.M. Paganica Church collapsed after earthquake and the PFRP spatial structure.
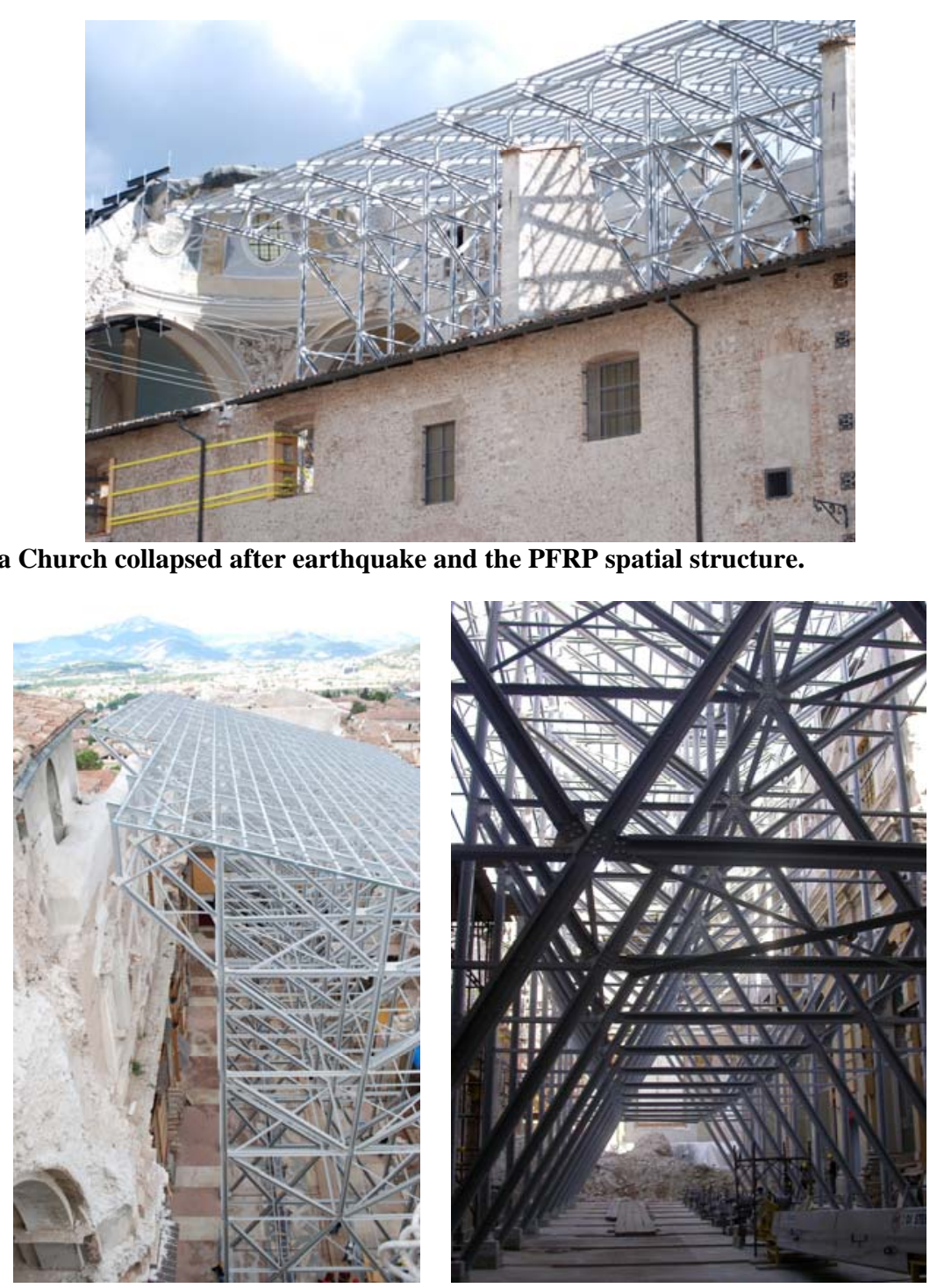

Fig. 2b The PFRP covering-structure inside of Church and in the back-ground the collapse of dome and ruins below. 


\section{Approach to Design and Analysis}

The calculation has been carried out with ultimate limit state method with both linear and non linear approach combining the effect of earthquake, wind and snow and the seismic several action derived by very high seismic zone as L'Aquila.

The lack of specific recommendations generates a conservative and dimensioning calculation. The first complication was by the uncertainly in adopting the structure coefficient needed in elastic spectrum definition and the damping coefficient that actually has been defined only for simply supported beam [12], frame [15] and structure [17].

Safety approach was globally adopted due not only to high light PFRP structure but also to face the risk of local and global instability in presence if dynamic action.

The loads correspondent to deformed structure derived by non linear analysis at ultimate limit state have been employed for a very punctual buckling analysis for each compressed element.

The designing joints in seismic zone was strongly influenced by the presence of steel-bolts and PFRP thus the crisis is characterized by local collapse of PFRP plate and never in steel bolts, [18]. However, the absence of plasticity has made a connection's design of hole very different than steel in term of number and configuration.

For PFRP structure the instability of compressed element gives the lower load of crisis used in ultimate limit state approach. The E/G ratio between elastic and shear moduli varying from 6 to 7 in steel becomes 1.5 to 2 for PFRP material.

The ultimate limit state method derived from Italian recommendation NTC08 as calculation has been applied with some conservative correction - for example the damping ratio $\zeta$ assumed $5 \%$ - that take in to account mechanical characteristics of PFRP material.

\section{FRP Material}

Mechanical performance of pultruded profiles and bag molding plates using in design are showed in Table 1; steel bolts employed are they usually employed in similar steel or aluminium construction.

\section{Numerical Analysis and Connections}

A commercial code calculation to determine the structural answer in face of wind, snow and seismic action has been utilized. The complexity of PFRP structure with 290 connection and 964 element to made frames and covering is shown in Fig. 3, while the first mode with the displacement along longitudinal direction and torsion implication in Fig. 4.

Table 1 Mechanical characteristics of plates and FRP profiles.

\begin{tabular}{|c|c|}
\hline E flexural $\mathrm{N} / \mathrm{mm}^{2}$ & 23000 \\
\hline E longitudinal $\mathrm{N} / \mathrm{mm}^{2}$ & 23000 \\
\hline E transversal (tension) $\mathrm{N} / \mathrm{mm}^{2}$ & 7000 \\
\hline $\mathrm{G} \mathrm{N} / \mathrm{mm}^{2}$ & 4000 \\
\hline Strength (tension./compr.) N/mm ${ }^{2}$ & 240 \\
\hline Flexural long.strength $\mathrm{N} / \mathrm{mm}^{2}$ & 240 \\
\hline Flexural Transversal strength $\mathrm{N} / \mathrm{mm}^{2}$ & 90 \\
\hline
\end{tabular}

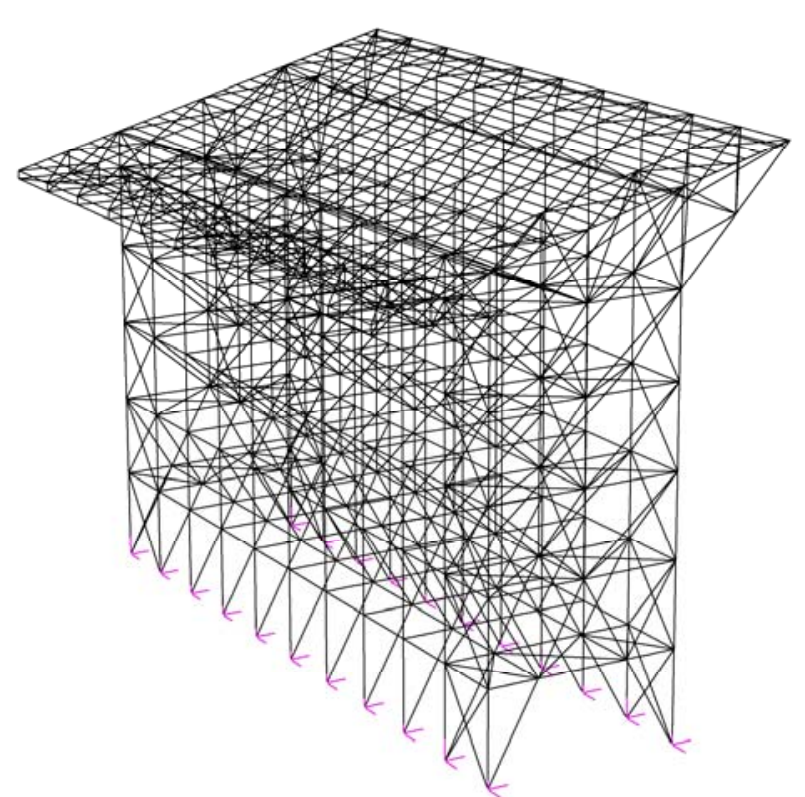

Fig. 3 Global view of numerical model (290 joints and 294 elements). 


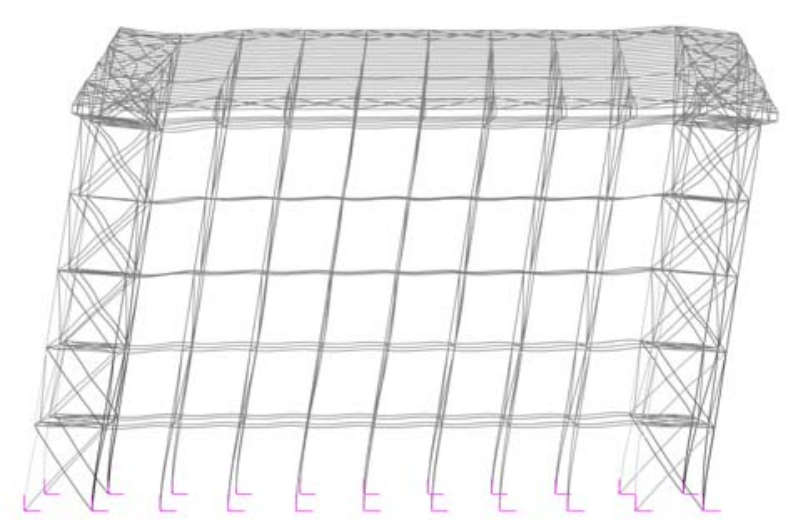

Fig. 4 Mode 1, 0.637s period.

The design structure and boundary condition characterized by emergency and very quickly decisional process have influenced the choice of PFRP element thus almost all elements have been realized only with cross pultruded section immediately available by producer. The basis structural cross section made by four "C" PFRP shape $(152 \times 46 \times 9.5$ $\mathrm{mm}$ ) connected through steel bolt to reduce also the risk of instability is showed in Fig. 5.

Some connection examples made by steel bolts, pultruded composite profiles and PFRP plate made by bag molding are illustrated in Fig. 6. To avoid the failure in PFRP plate a thickness overestimation were realized facing bearing and considering the higher difference in term of stiffness than steel; the crisis at ultimate limit state leads by local failure in PFRP plate.

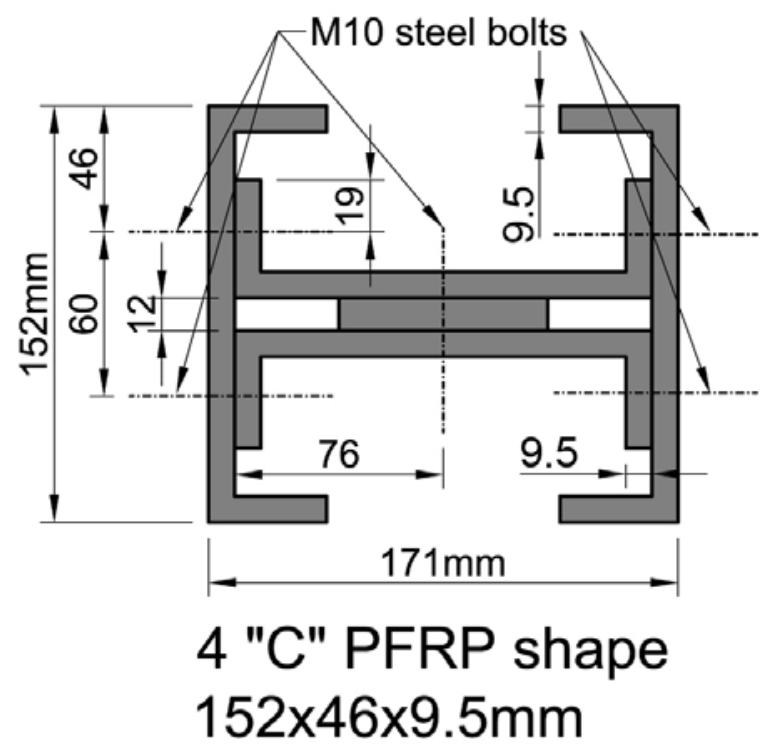

Fig. 5 Basic cross section made by four "C" PFRP profiles.
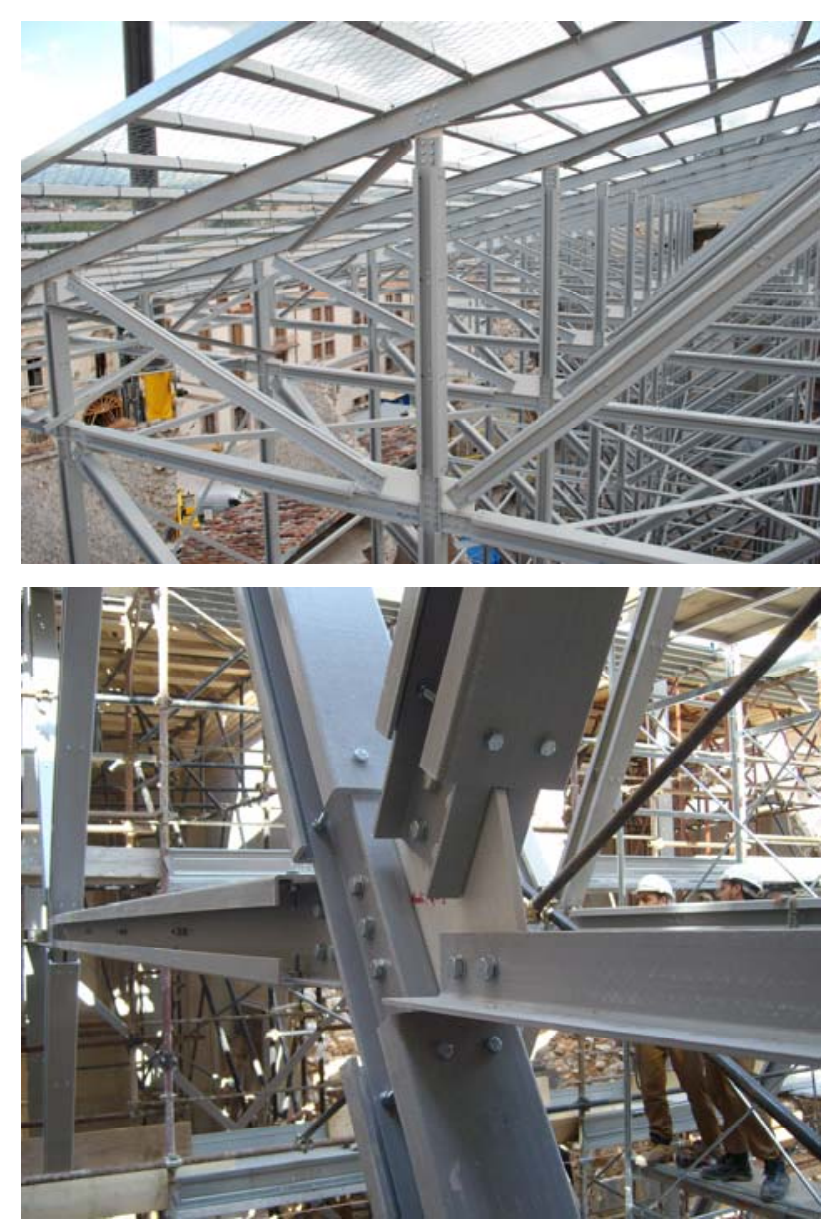

Fig. 6 PFRP-steel connections.

\section{The Yard}

In Fig. 7, it shows a yard's phases, i.e., assembling way of frame, preassembling of truss outside church and final covering.

\section{First Conclusions}

On the basis of described results the following considerations can be proposed:

- in spite of lightness PFRP material, the spatial structure exhibit $1.57 \mathrm{~Hz}$ first mode vibration that leads very stiff behavior;

- first mode vibration exhibit $0.64 \mathrm{~s}$ period with $70 \%$ mass involved and finally the $98 \%$ mass in two principal direction.

- the numerical calculation in a big lack of specific recommendation in seismic field can be done using traditional commercial code with not so high conservative results, as showed, with structure 

for Historic Structure Stroked by Earthquake
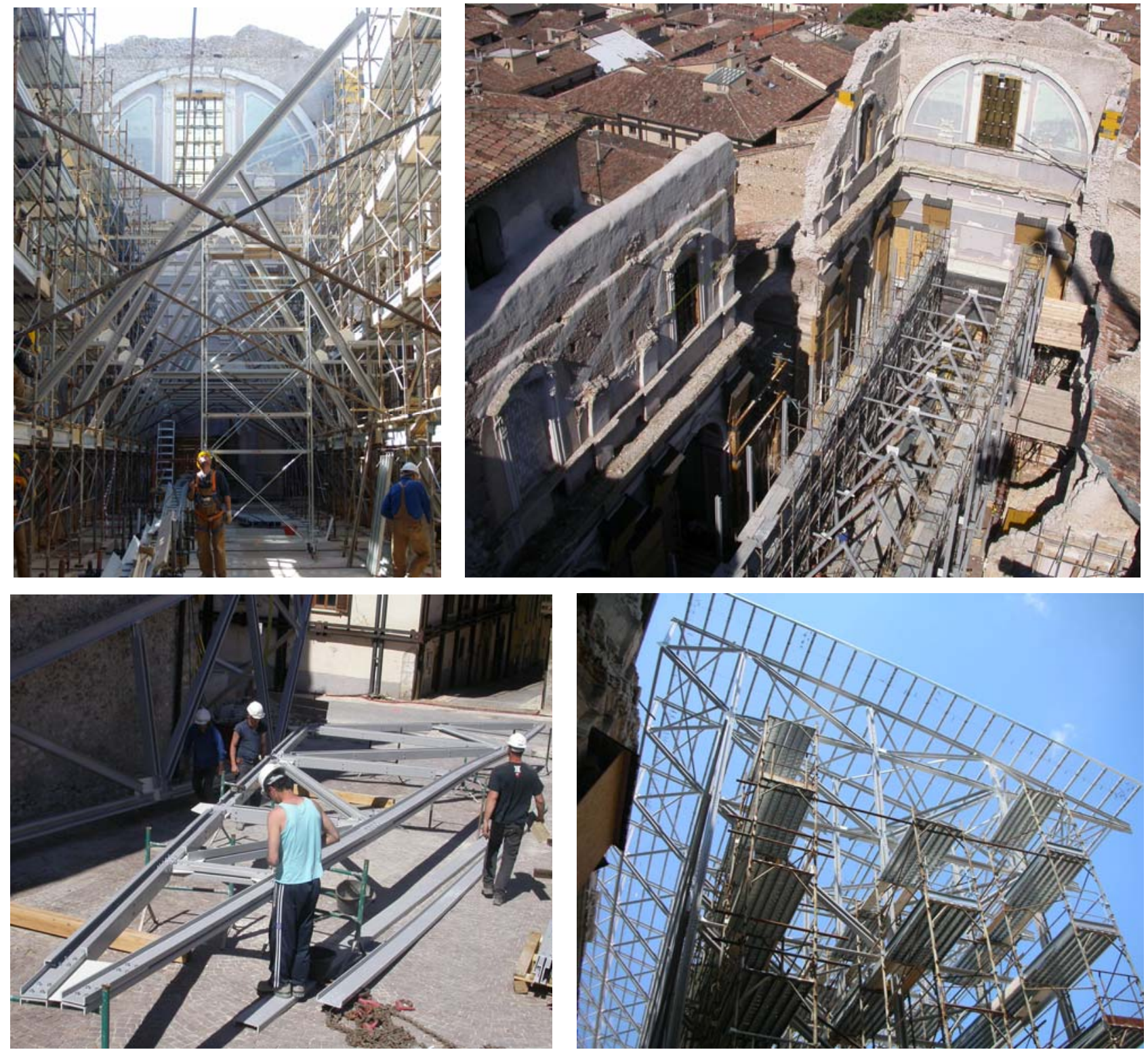

Fig. 7 Yard's phases.

coefficient structure $\mathrm{q}=1$ to define the spectrum at ultimate limit state assumed;

- the connection and basic composed element avoiding the instability with acceptable and reasonable thin of PFRP plate also from economic point of view has been specifically designed;

- the perspective's employment of PFRP structures in seismic zone seems to be very promising, and yard's phases have been characterized by easy assembly.

\section{References}

[1] S. Russo and M. Silvestri, Perspectives of employment of pultruded FRP structural elements in seismic engineering field, in: Seismic Eng. Int. Conf. Commemorating the 1908 Messina and Reggio Calabria Earthquake, MERCEA08, Reggio Calabria, July 8-11, 2008, pp. 1103-1112.

[2] ASCE, Structural Plastic Design Manual (vol. 1, e 2), ASCE American Society of Civil Engineers, 1984.

[3] L. C. Bank, Composites for Construction, Structural Design with FRP Materials, John Wiley and Sons, INC., 2006. 

for Historic Structure Stroked by Earthquake

[4] J. L. Clarke, Structural Design of polymer composites, in: L. John, E. Clarke and F. N. Spon (Eds.), Design Code and Hnadbook, EUROCOMP 1996.

[5] S. Russo, Buckling of GFRP pultruded columns, in: International Conference "Composites in Construction", Porto, Portugal, 2001.

[6] S. Russo, Creep on GFRP structural shape, in: International conference "Composites in Construction", Porto, Portugal, 2001.

[7] S. Russo and A. Di Tommaso, Shape influence in buckling of GFRP pultruded column, Journal of Mechanics of Composite Materials 39 (4) (2003) 329-340.

[8] S. Russo, Strutture in composito - Sperimentazione, teoria e applicazioni, HOEPLI 2007.

[9] CNR-DT (205/2007), Istruzioni per la progettazione, l'esecuzione ed il Controllo di Strutture realizzate con profili Sottili pultrusi di materiale composito fibrorinforzato (FRP).

[10] S. Russo and G. Boscato, On mechanical performance of different type of FRP beams as reinforcement of pedestrian bridge, in: IABMAS'08 The Fourth International Conference on Bridge Maintenance, Safety and Management, Seoul, Korea, July 13-17, 2008.

[11] S. Russo and A. Adilardi, Innovative design approach to a GFRP pedestrian bridge: Structural aspects, engineering optimization and maintenance, bridge maintenance, safety, management and life-cycle optimization, in: Proceedings of the 5th International
Conference on Bridge Maintenance, Safety and Management, 2010, pp. 2455-2459.

[12] G. Boscato and S. Russo, Free vibration of pultruded FRP elements: Mechanical characterization, analysis and applications, Journal of Composites for Construction 13 (6) (2009) 565-574.

[13] G. Boscato and S. Russo, GFRP structures subjected to dynamic action, in: CICE2010 Conference, Department of Civil Engineering Tsinghua University Beijing, China, 27-29 Sep. 2010.

[14] G. Boscato and S. Russo, GFRP members in free vibrations field, dynamic parameters of profiles and $3 \mathrm{D}$ structure, in: CICE2010 Conference, Department of Civil Engineering Tsinghua University Beijing, China, 27-29 Sep. 2010.

[15] G. Boscato, Dynamic Behaviour of GFRP Pultruded Elements, Published by University of Nova Gorica, Nova Gorica, Slovenia, 2011.

[16] G. Boscato, J. T. Mottram ans S. Russo, Dynamic response of a sheet pile of fiber reinforced polymer for waterfront barriers, Journal of Composites for Construction 15 (6) (2011).

[17] S. Russo, Experimental and finite element analysis of a very large pultruded FRP structure subjected to free vibration, Composite Structures 94 (3) (2012) 1097-1105.

[18] J. T. Mottram and Y. Zheng, Further tests on Beam-to-Column Connections for Pultruded Frames: Web-Cleated, Journal of Composites for Construction 3 (1) (1999). 